NASA Technical Memorandum 106480

\title{
Determination of Copper in Tap Water Using Solid-Phase Spectrophotometry
}

Carol M. Hill

University of Akron

Akron, Ohio

Kenneth W. Street and Warren H. Philipp

Lewis Research Center

Cleveland, Ohio

and

Stephen P. Tanner

University of West Florida

Pensacola, Florida

May 1994

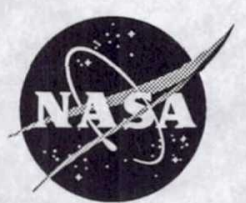

National Aeronautics and

Space Administration 
Trade names or manufacturers' names are used in this report for identification only. This usage does not constitute an official endorsement, either expressed or implied, by the National Aeronautics and Space Administration. 


\title{
DETERMINATION OF COPPER IN TAP WATER USING SOLID-PHASE SPECTROPHOTOMETRY
}

\author{
Carol M. Hill ${ }^{1}$ \\ University of Akron \\ Akron, Ohio 44325 \\ Kenneth W. Street ${ }^{2}$ and Warren H. Philipp \\ National Aeronautics and Space Administration \\ Lewis Research Center \\ Cleveland, Ohio 44135 \\ Stephen P. Tanner \\ University of West Florida \\ Pensacola, Florida 32514
}

\section{ABSTRACT}

A new application of ion exchange films is presented. The films are used in a simple analytical method of directly determining low concentrations of $\mathrm{Cu}^{2+}$ in aqueous solutions, in particular, drinking water. The basis for this new test method is the color and absorption intensity of the ion when adsorbed onto the film. The film takes on the characteristic color of the adsorbed cation, which is concentrated on the film by many orders of magnitude. The linear relationship between absorbance (corrected for variations in film thickness) and solution concentration makes the determinations possible. These determinations agree well with flame atomic absorption determinations.

\section{INTRODUCTION}

Copper is essential to human metabolism, but too much copper can cause stomach and intestinal distress and a form of Wilson's disease. The United States' Safe Drinking Water Act recommends an acceptable $\mathrm{Cu}^{2+}$ level of $1.3 \mathrm{ppm}$ in drinking water. ${ }^{3}$ Unfortunately, when copper pipes in older homes corrode, the $\mathrm{Cu}^{2+}$ content in the water can rise above the recommended level. Therefore, there is a need for a simple, inexpensive home screening method to determine $\mathrm{Cu}^{2+}$ content in tap water.

A new cationic ion-exchange material (IEM) in the form of thin films effectively removes undesirable metal cations from aqueous solution. This material, which was originally developed as an insulator for separating the metallic plates in alkali voltaic cells used in space vehicles, ${ }^{4-6}$ is easily produced in the form of an optically transparent film. It has several advantages over commercial resins. In many resins, $\mathrm{Ca}^{2+}$, normally present in natural waters, competes with the metal ions for sites on the resin, thus rendering the resin beads less effective. One advantage of this new IEM is that it is more effective in the $\mathrm{Ca}^{2+}$ form than in either the acid or $\mathrm{Na}^{+}$forms. 
Metal ion adsorption on the new IEM is especially noticeable when the metal ions have characteristic colors associated with them. This observation led to a new method for solid-phase spectrophotometry (SPS). SPS preconcentrates the analyte onto a solid substrate (usually ion-exchange resin beads); then, after a chromophoric complexing agent is added, a spectrophotometric measurement of the substrate is made. ${ }^{7}$ This method has been demonstrated successfully for numerous elements and various matrices. ${ }^{7-11}$, and references therein However, the beads are not ideal optical media, and even with refractive index matching, measurement of the developed color is cumbersome. The proposed method involves the new ion-exchange resin in the form of optically transparent films. Metal ions are adsorbed directly onto the resin, which then becomes colored if the ions have a characteristic color. The absorbance is measured directly, eliminating the need for chromophoric developers. Test results for tap water samples indicate a good correlation between the proposed method and the standard atomic absorption spectrometer (AAS) procedure.

\section{EXPERIMENTAL METHODS}

Materials

In these experiments the acid form of the film (which was approximately $0.1-\mathrm{mm}$ thick) was first converted to either the $\mathrm{Ca}^{2+}$ or $\mathrm{Na}^{+}$form by treatment with the corresponding base. A Specpure copper ICAP Standard (Johnson Matthey Company), 1000-ppm Cu${ }^{2+}$, in 5 vol \% $\mathrm{HNO}_{3}$ was used to prepare working standards by serial dilution, and the $\mathrm{pH}$ was appropriately adjusted with dilute acid or base. All other reagents and solvents were of analytical-reagent grade (Fisher Scientific), and deionized water was used throughout. The IEM film fabrication is complex and will be described in a future paper devoted to this topic.

\section{Apparatus}

Fowler \& NSK Max-Series Electronic Digital Calipers was used to measure sample dimensions. A Perkin Elmer AAS, Model 3100, equipped with a PC Craft work station was used in the normal mode of operation. All pH measurements were made with a Corning Model $130 \mathrm{pH}$ meter equipped with combination $\mathrm{pH}$ and automatic-temperature-compensating electrodes, and absorbance measurements were made with a Shimadzu model UV 160 recording spectrophotometer equipped with standard $1-\mathrm{cm}^{2}$ quartz cells and 9-mm quartz spacers. 


\section{Procedures}

Copper Calibration Curve (High Concentration). A 200-ml sample of the desired $\mathrm{Cu}^{2+}$ concentration ( 0 to $30 \mathrm{ppm}$ ) was prepared in a glass jar with a Teflon-lined lid, and the $\mathrm{pH}$ was then adjusted to approximately 5.0. An initial sample of the solution was removed, preserved with $\mathrm{HNO}_{3}$, and set aside for AAS analysis. Then, exactly $60 \mathrm{mg}$ of dry $\mathrm{Ca}^{2+}$ film was cut, and its dimensions were measured with calipers. (The film was approximately 1 by $6 \mathrm{~cm}$, to fit directly into a standard 1-cm cuvette.) It was placed into the $\mathrm{Cu}^{2+}$ solution and stirred for $24 \mathrm{hr}$, and a similarly treated film sample was placed into a deionized water blank. After $24 \mathrm{hr}$ of mixing, the films were removed. The remaining solutions were acidified, and both initial and final solutions were analyzed by AAS. ${ }^{12}$ The AAS conditions employed for all analyses were analytical wavelength, $324.8 \mathrm{~nm}$; slit width, $0.7 \mathrm{~nm}$; aspiration rate, $9 \mathrm{ml} / \mathrm{min}$; and flame, air-acetylene (lean).

The visible spectra of the films were recorded over the 400- to $1000-\mathrm{nm}$ range versus a blank film. The film was placed in a standard $1-\mathrm{cm}^{2}$ cell, along with a 9-mm spacer, and deionized water was added to optically couple the film system. The minimum absorbance reading at $480 \mathrm{~nm}$ was subtracted from the maximum at $710 \mathrm{~nm}$, thus correcting the baseline offset. Then, the offset-corrected absorbance multiplied by the area of film in square millimeters was plotted versus initial concentration of the metal ions in ppm.

$\mathrm{pH}$ Study. Solutions of $15-\mathrm{ppm} \mathrm{Cu}^{2+}$ were prepared as described, and the $\mathrm{pH}$ adjusted to the desired value. An initial sample was removed for AAS analysis. Then, exactly $40 \mathrm{mg}$ of dry $\mathrm{Ca}^{2+}$ film was placed into each of these solutions. The $\mathrm{pH}$ was monitored over several hours after the addition of the film, adjusting as necessary to maintain the desired $\mathrm{pH}$. Once the $\mathrm{pH}$ stabilized, the system was allowed to equilibrate for $24 \mathrm{hr}$, with constant stirring. After $24 \mathrm{hr}$, the film was removed, the final $\mathrm{pH}$ of the system was measured, and the solution was acidified for AAS analysis. The films were also analyzed for the metal ion content, and a plot of the fraction of metal ion removed versus the $\mathrm{pH}$ was constructed.

Destructive Film Analysis Procedures. The film was boiled in $5 \mathrm{ml}$ of concentrated $\mathrm{HNO}_{3}$ with $1 \mathrm{ml}$ of concentrated $\mathrm{HCl}$ for $15 \mathrm{~min}$ to ensure complete dissolution. If the film did not dissolve fully, additional $\mathrm{HNO}_{3}$ was added and the solution was boiled for another $5 \mathrm{~min}$. After dissolution, the solution was diluted to a known volume with deionized water for AAS analysis.

Kinetics Study. Samples of $15-\mathrm{ppm} \mathrm{Cu}^{2+}$ were prepared by adjusting the $\mathrm{pH}$ to 5.0 and diluting the solution to $200 \mathrm{ml}$. Exactly $120 \mathrm{mg}$ of dry film, in either the $\mathrm{Ca}^{2+}$ form or the $\mathrm{Na}^{+}$form, was added to two of the solutions. Samples of Fisher Amberlite IR-120 (16-50 mesh) hydrogen-form ion-exchange beads and of BIO-RAD AG 50W-X8 (200-400 mesh) hydrogen-form ion-exchange beads were converted into either the $\mathrm{Ca}^{2+}$ form or the $\mathrm{Na}^{+}$form. Then, $130 \mathrm{mg}$ of these beads was added to $15-\mathrm{ppm} \mathrm{Cu}^{2+}$ solutions 
as before. Aliquots of each solution were removed after known time intervals and analyzed. Finally, the amount of $\mathrm{Cu}^{2+}$ remaining in solution was plotted versus time. All solutions were stirred at a constant rate at room temperature. Comparisions were made between experiments that were run concurrently to minimize the effects of any fluctuations in temperature.

Tap Water Determinations and Calibration Curve (Low Concentration). Copper standards (0 to $2 \mathrm{ppm}$ ) were prepared, the $\mathrm{pH}$ was adjusted to 5.0, and an initial sample was removed for AAS analysis. Exactly $60 \mathrm{mg}$ of dry $\mathrm{Ca}^{2+}$ film was cut, measured with the calipers, and placed into $2000 \mathrm{ml}$ of the standard. A similar blank was prepared with deionized water. The solutions were stirred for $48 \mathrm{hr}$. After the films were removed, the remaining solutions were acidified for AAS analysis. Then the spectra of the films were recorded, and a calibration curve was prepared as previously described. Samples of tap water were treated identically, and the concentrations were determined from the calibration curve.

\section{RESULTS AND DISCUSSION}

\section{Film Properties}

The IEM used in this method is a new weak acid ion-exchange polymer film that is optically clear, mechanically strong, and thermally stable. The $\mathrm{pH}$ study illustrates the ability of the $\mathrm{Ca}^{2+}$ form of the IEM (Ca-IEM) to take up $\mathrm{Cu}^{2+}$ (Fig. 1). In all other experiments, we chose a pH of 5.0; because below its $\mathrm{pK}_{\mathrm{a}}$, the film reverts to the acid form, which is not effective in removing the $\mathrm{Cu}^{2+}$. Above a pH of 7 , the solubility of $\mathrm{Cu}(\mathrm{OH})_{2}$ governs the IEM uptake.

The kinetic curves for $\mathrm{Cu}^{2+}$ uptake by the IEM indicate that the $\mathrm{Ca}^{2+}$ form of the film is the most effective in removing the metal. As can be seen in Figure $2 b$, the $\mathrm{Na}^{+}$form adsorbs the $\mathrm{Cu}^{2+}$ faster initially; however, at equilibrium it is not as effective as the $\mathrm{Ca}^{2+}$ form. A parallel study conducted with 100-ppm $\mathrm{Ca}^{2+}$ in 15-ppm $\mathrm{Cu}^{2+}$ indicates that the interference of $\mathrm{Ca}^{2+}$ in the uptake of $\mathrm{Cu}^{2+}$ is negligible (Table 1).

TABLE 1

Copper Uptake by Ca-IEM After 24 hr of Equilibration at $\mathrm{pH}=5.0$

\begin{tabular}{lcc}
\hline \multicolumn{1}{c}{ Sample } & \multicolumn{2}{c}{$\begin{array}{c}\text { Concentration } \\
(\mathrm{ppm})\end{array}$} \\
\cline { 2 - 3 } & Initial & Final \\
\hline Copper standard & 14.1 & 0.8 \\
Copper standard $+100 \mathrm{ppm} \mathrm{Ca}^{2+}$ & 14.2 & 1.9 \\
\hline
\end{tabular}


Commercially available ion-exchange beads also remove $\mathrm{Cu}^{2+}$ from aqueous media; however, they are not as efficient in the $\mathrm{Ca}^{2+}$ form. The results of the kinetic study of two such resin beads yield similar curves (Fig. 2a). The equilibrium concentrations of the $\mathrm{Ca}^{2+}$ and $\mathrm{Na}^{+}$curves are reversed in comparison to the curves of the IEM film.

The equilibrium constants for the new IEM were also calculated and were compared to literature values. For ion-exchange reactions,

$$
\begin{aligned}
M+\mathrm{Ca}_{R} & \rightleftharpoons \mathrm{Ca}+M_{R} \\
M+2 \mathrm{Na}_{R} & \rightleftharpoons 2 \mathrm{Na}+M_{R}
\end{aligned}
$$

where $\mathrm{M}, \mathrm{Ca}$, and $\mathrm{Na}$ are ions in solution, the subscript $R$ indicates that metal bound to the resin and charges have been omitted. For example, the exchange constant, $K_{e x}$ for reaction (2) is given in equation (3) for the uptake of arbitrary metal, $\mathrm{M}^{2+}$ :

$$
K_{e x}^{\mathrm{Na}}=\frac{[\mathrm{Na}]^{2}\left[\mathrm{M}_{R}\right]}{\left[\mathrm{Na}_{R}\right]^{2}[\mathrm{M}]}
$$

The exchange constants were calculated and compared with the literature values ${ }^{13}$ for Dowex 50 (4\% Divinyl Benzene crosslink) for the uptake of $\mathrm{Cu}^{2+}$. For the $\mathrm{Ca}^{2+}$ and $\mathrm{Na}^{+}$forms of Dowex, the calculated values for copper uptake are 0.84 and 0.63 , respectively. This indicates that $\mathrm{Ca}^{2+}$ inhibits the uptake of $\mathrm{Cu}^{2+}$, which was experimentally confirmed by the results for the Amberlite and BIO-RAD resins. For comparison, the calculated exchange constant for $\mathrm{Cu}^{2+}$ uptake for the $\mathrm{Ca}^{2+}$ form of the IEM is 1.07 , indicating a more efficient process. If a purely electrostatic exchange mechanism operated, the new IEM would behave similarly to the other resins. The curve reversal indicates that processes other than electrostatic attractions play a key role in the uptake of $\mathrm{Cu}^{2+}$. The exact mechanism for this effect is still under investigation.

\section{Solid-Phase Spectrophotometric Determination of Copper}

The spectra from the calibration curves indicate an offset in the baseline due to film inconsistencies (Fig. 3). Therefore, the baseline offset corrected absorbance, $A_{\text {corr }}$, was calculated (eq. (4)). 


$$
A_{\text {corr }}=A_{710 \mathrm{~nm}}-A_{480 \mathrm{~nm}}
$$

For quantification, absorbance multiplied by the area of the film was used instead of absorbance because although the weight remained constant, the thickness and area varied slightly. For seven standards including blanks, the areas ranged from 564 to $622 \mathrm{~mm}^{2}$. When area corrections are applied, a linear plot results with a slope and intercept of $50-\mathrm{mm}^{2} \bullet A \bullet \mathrm{ppm}^{-1}$ and $4-\mathrm{mm}^{2} \bullet A$, respectively, and a correlation coefficient of 0.994 . Modified Beer's law plots can be constructed by using either area or $b^{-1}$ to normalize the variations in film thickness; we chose area because its measurement is less sensitive to inhomogeneities in the film.

A visual color chart of $\mathrm{Cu}^{2+}$ concentrations was constructed from the films. This chart provides a quick approximation of the $\mathrm{Cu}^{2+}$ concentration in unknown samples (Fig. 4).

For quantitative SPS analysis, calibration curves were constructed. In these experiments, the amount of film used provided at least a 4-fold excess of exchange sites over metal ions. Separate calibration curves, both linear, were obtained for high and low concentration ranges. They are useful in different applications. For example, the low concentration range is useful in determining tap water concentrations, and the high concentration range may be useful for electroplating applications.

A 2000-ml sample of tap water and $60 \mathrm{mg}$ of film were used because only small amounts of $\mathrm{Cu}^{2+}$ are found in tap water. For the low-concentration calibration curve experiments, the standards and samples were allowed to stir for $48 \mathrm{hr}$ instead of $24 \mathrm{hr}$ because of mass transport problems. There is more scatter in the data, and recoveries are lower for the 24 -hr experiments. (The 48 -hr recovery was $55 \pm 4$ percent as opposed to $39 \pm 5$ percent for the $24-\mathrm{hr}$ recovery.)

Three sources of tap water were analyzed by this method, and there is excellent agreement with the AAS determinations (Table 2). This new method has the advantage of producing a permanent color change in the film. Thus, spectrophotometric measurements can be made long after equilibration, and the colored film can be stored to provide a permanent record. Calibration curves constructed from measurements made on these films remained unchanged after 10 months of storage. 
TABLE 2

Determination of Copper in Tap Water

\begin{tabular}{ccc}
\hline Sample & \multicolumn{2}{c}{$\begin{array}{c}\text { Concentration determined } \\
(\mathrm{ppm})\end{array}$} \\
\cline { 2 - 3 } & SPS method & AAS method \\
\hline Tap 1 & 0.65 & 0.66 \\
Tap 2 & .15 & .15 \\
Tap 3 & .18 & .17 \\
\hline
\end{tabular}

Other colored metals, including $\mathrm{Fe}^{3+}, \mathrm{Ni}^{2+}, \mathrm{Cr}^{3+}$, and $\mathrm{Co}^{2+}$, will obscure the simple color chart method; however, each colored metal ion absorbs at a different wavelength (Fig. 5). Spectrophotometrically, it is possible to resolve them as a multicomponent system. In tap water, however, the only plausible interference might be $\mathrm{Fe}^{3+}$. Fortunately, ferric hydroxide precipitates well below $\mathrm{pH} 5$, and no evidence of $\mathrm{Fe}^{3+}$ was apparent either by eye or in the spectrum for any film sample. Ferric ion was not taken up from standards by the IEM under the conditions employed for tap water determinations.

\section{CONCLUSIONS}

Novel ion-exchange films take on the characteristic color associated with metal ions. Advantages of this new ion-exchange material include its immunity to $\mathrm{Ca}^{2+}$ interference and ability to be constructed in several different forms, including optical films. Films are easy to handle and to recover from samples, providing a permanent record of the analysis. The color of the ion on the film and its intensity are the basis for a new method of determining $\mathrm{Cu}^{2+}$ in tap water which agrees well with parallel AAS determinations. Using the visual color chart for determining $\mathrm{Cu}^{2+}$ concentration in tap water is a simple, inexpensive procedure that can be performed, with minor modifications, in the home.

\section{ACKNOWLEDGMENTS}

This work was supported by NASA Lewis Research Center through the Director's Discretionary Fund and a NASA-ASEE Fellowship to S.P.T. The authors thank the Chemical Sampling and Analysis Office staff for their assistance and encouragement during this research. 


\section{REFERENCES}

1. Student Intern at NASA Lewis Research Center. Present Address: University of North Carolina, Department of Chemistry, CB \#3290, Venable Hall, Chapel Hill, North Carolina 27599-3290.

2. Corresponding Author.

3. $\quad$ EPA Regulations: Drinking Water: 40 CFR 141.80 (c)(2).

4. Philipp, W.H., May, C.E., and Hsu, L-C., "New lon-Exchange Membranes," NASA TM-81670 (1980).

5. Philipp, W.H., and May, C.E. "Kinetics of Copper Ion Absorption by Cross-Linked Calcium Polyacrylate Membranes," NASA TM-83052 (1983).

6. May, C.E., and Philipp, W.H., "Ion Exchange Selectivity for Cross-Linked Polyacrylic Acid," NASA TM-83427 (1983).

7. Capitán, F., Capitán-Vallvey, L.F., Bosque-Sendra, J.M., Molina, F., and de Orbe, I. Analysis, 19 (1991), 177-179.

8. Bosque-Sendra, J.M., Valencia, M.C., and Capitán-Vallvey, L.F., Int. J. Environ. Anal. Chem., 38 (1990), 551-559.

9. $\quad$ Capitán, F., Roman Navarro, J.M., Capitán-Vallvey, L.F., Anal. Lett., 24(7) (1991), 1201-1217.

10. Bosque-Sendra, J.M., Molina, F., and Lopez, E., Analyst, 116 (1991), 871-874.

11. Fernandez-DeCordova, M.L., Molina-Diaz. A., and Pascual-Reguera, M.I., Anal. Lett., 25(10) (1992), 1961-1980.

12. EPA Analysis: SW-846 EPA Method 3005, EPA Method 7201.

13. A. Ringbom "Complexation in Analytical Chemistry, "R.E. Krieger Publishing Co., Inc., Huntington, New York (1963), 201-204. 


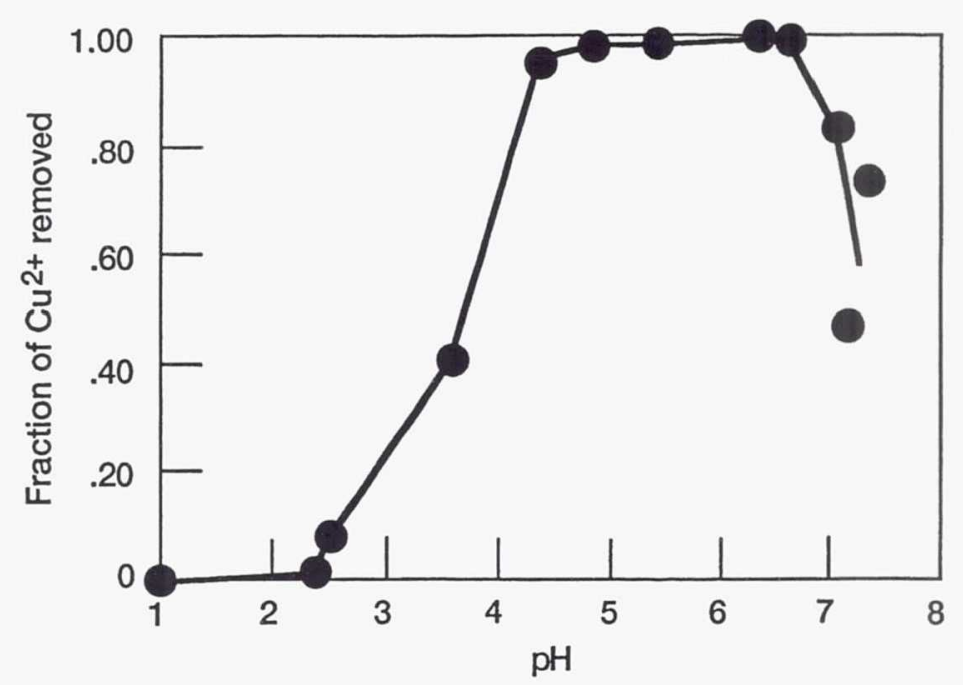

Figure 1.-Fraction of $\mathrm{Cu}^{2+}$ removed by $\mathrm{Ca}$-IEM as a function of $\mathrm{pH}$.
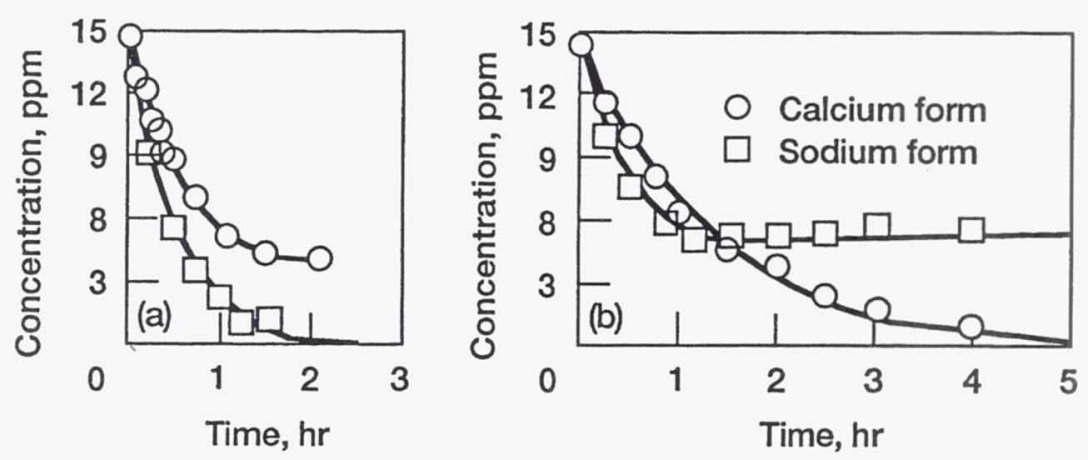

Figure 2.-Time-dependent depletion of $\mathrm{Cu}^{2+}$ from solution by ion-exchange resins. (a) Amberlite resin at $\mathrm{pH} 5.5$ and (b) IEM at pH 5.5.

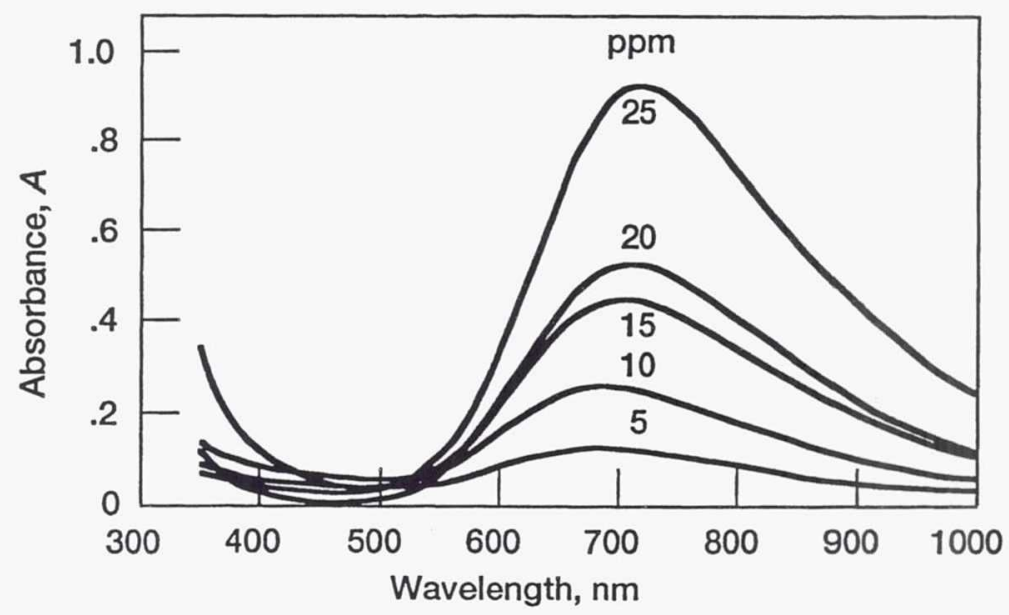

Figure 3.-Spectra of $\mathrm{Ca}-\mathrm{IEM}$ equilibrated with $\mathrm{Cu}^{2+}$ standards at $\mathrm{pH}$ 5.0. 
Page intentionally left blank 


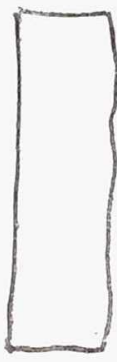

0.0

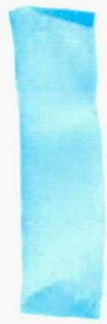

0.5

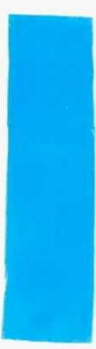

1.5

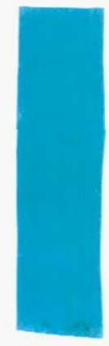

3.0

$$
\mathrm{Cu}^{2+} \text { concentration, } \mathrm{ppm}
$$

Figure 4.-Color comparison chart for visual determination of $\mathrm{Cu}^{2+}$ in water.
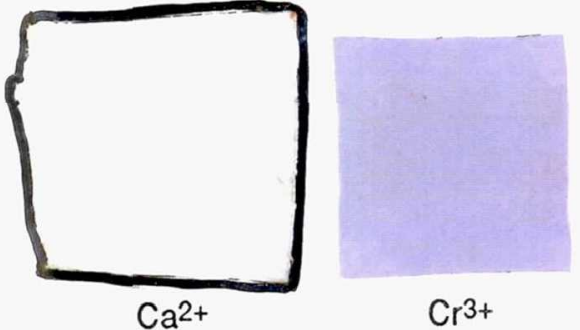

$\mathrm{Cr} 3+$

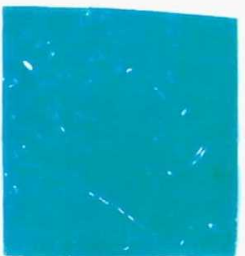

$\mathrm{Cu}^{2+}$

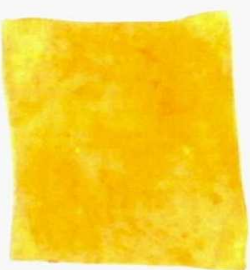

$\mathrm{Fe}^{3+}$

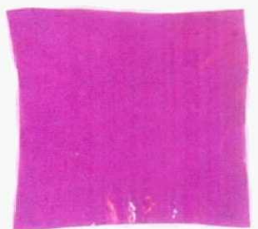

$\mathrm{Co}^{2+}$

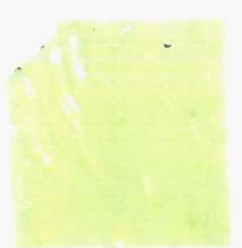

$\mathrm{Ni} 2+$

Figure 5.-Colors of metal ions adsorbed on ionexchange films. 


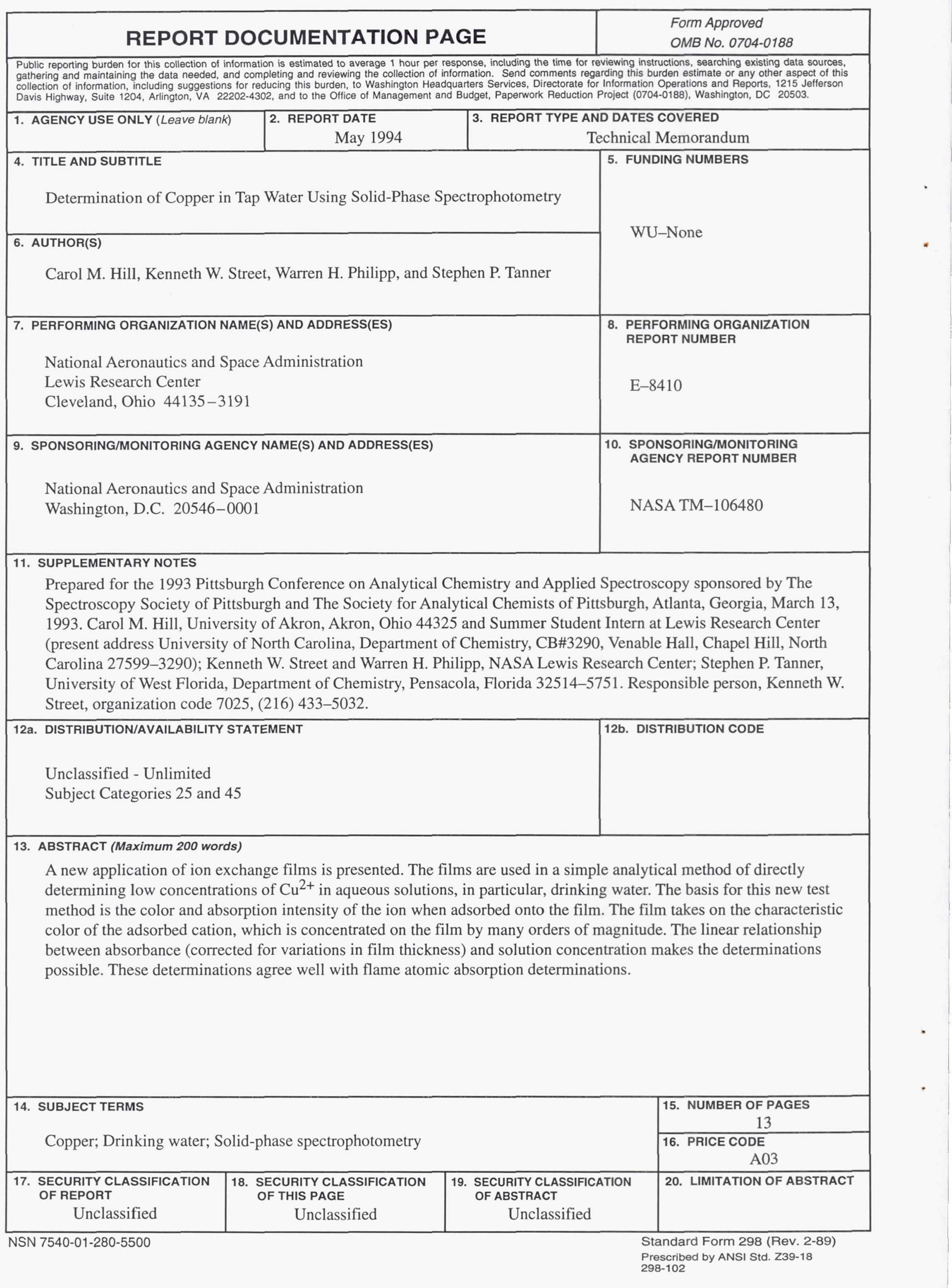

